\title{
Release of Fragrances from Cotton Functionalized with Carbohydrate-Binding Module Proteins
}

\author{
Filipa Gonçalves, ${ }^{\dagger}$ Artur Ribeiro, $^{\dagger}$ Carla Silva, ${ }^{*}{ }^{\dagger}$ and Artur Cavaco-Paulo* ${ }^{*} \dagger$ (i) \\ ${ }^{\dagger}$ Centre of Biological Engineering, University of Minho, Campus de Gualtar, 4710-057, Braga, Portugal
}

Supporting Information

ABSTRACT: Perspiration as a response to daily activity and physical exercise results in unpleasant odors that cause social unrest and embarrassment. To tackle it, functional textiles incorporating fragrances could be an effective clothing deodorizing product. This work presents two strategies for the release of $\beta$-citronellol from functionalized cotton with carbohydrate-binding module (CBM)-based complexes (OBP:: $\mathrm{GQ}_{20}:: \mathrm{CBM} / \beta$-citronellol-approach 1 and CBM::GQ ${ }_{20}$ ::SP-DS3-liposome/ $\beta$-citronellol-approach 2 ). $\mathrm{CBM}$ from Cellulomonas fimi was fused with the odorant-
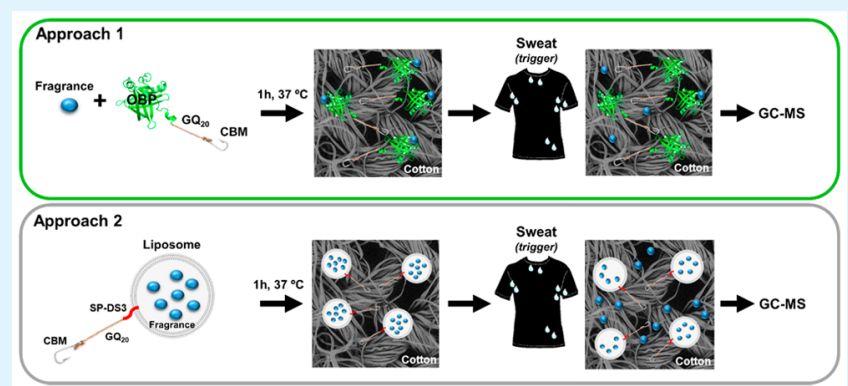
binding protein (OBP:: $\mathrm{GQ}_{20}:: \mathrm{CBM}$ ) and with an anchor peptide with affinity to the liposome membrane (CBM::GQ $\left.{ }_{20}:: S P-D S 3\right)$. In approach 1 , OBP fusion protein served as a fragrance container, whereas in approach 2 , the fragrance was loaded into liposomes with a higher cargo capacity. The two strategies showed a differentiated $\beta$-citronellol release profile triggered by an acidic sweat solution. OBP::GQ $20: \mathrm{CBM}_{2}$ complex revealed a fast release $(31.9 \%$ and $25.8 \%$ of the initial amount, after 1.5 and $24 \mathrm{~h}$ of exposure with acidic sweat solution, respectively), while the $\mathrm{CBM}:: \mathrm{GQ}_{20}:: S P-D S 3-$ liposome complex demonstrated a slower and controlled release (5.9\% and $10.5 \%$ of the initial amount, after 1.5 and $24 \mathrm{~h}$ of exposure with acidic sweat solution, respectively). Both strategies revealed high potential for textile functionalization aimed at controlled release of fragrances. The OBP::GQ ${ }_{20}: \mathrm{CBM} / \beta$-citronellol complex is ideal for applications requiring fast release of a high amount of fragrance, whereas the CBM::GQ ${ }_{20}:: S P-D S 3-l i p o s o m e / \beta$ citronellol complex is more suitable for prolonged and controlled release of a lower amount of $\beta$-citronellol.

KEYWORDS: carbohydrate-binding module, fragrance, liposomes, odorant-binding protein, controlled release, SP-DS3 peptide

\section{INTRODUCTION}

In response to unpleasant odors resultant from daily activity and physical exercise, there is an increasing need for safe and effective clothing deodorizing products. ${ }^{1,2}$ Smart textiles have arisen as new textiles that can incorporate functional elements added in finishing of textiles and may respond to changes like light, temperature, mechanical stress, or humidity. ${ }^{3}$ The use of fragrances is often essential to create an elegant and welcoming environment, particularly in daily social interplay. ${ }^{4}$ This way, the encapsulation and release of fragrances from functionalized fabrics has arisen as a great strategy for the development of stimulus responsive cosmetotextiles. Abdelkader et al. described the preparation of nanocapsules containing 2ethoxynaphthalene (neroline) fragrance by interfacial polycondensation method for cotton functionalization. ${ }^{5} \mathrm{Hu}$ et al. ${ }^{6}$ produced polybutylcyanoacrylate (PBCA) nanocapsules encapsulating rose fragrance and evaluated its release from cotton fabrics by gas chromatography-mass spectrometry (GC-MS). ${ }^{6}$ Some studies showed that the complexation of $\beta$-cyclodextrins with fragrances allow retention of fragrances for a long period of time. An example of cyclodextrin application in textile processing is on the entrapment of aroma from sweat and cigarette smoke. Despite all the strategies already developed and implemented for fragrance release in textiles, other approaches have emerged for the functionalization of textile surfaces, namely based on stimulus-responsive materials.

Carbohydrate-binding modules (CBMs), previously named cellulose-binding domains (CBDs), are noncatalytic modules of enzymes promoting the association of the enzyme to the substrate. $^{8-10}$ These modules have been used for the functionalization of fibers in paper and textile industries. For example, the $\mathrm{CBM}_{\mathrm{N} 1}$ from Cellumonas fimi cellulase has the capacity to be adsorbed on cotton at $\mathrm{pH}$ of around 7 for long periods of time without damaging cellulose. ${ }^{11}$ Cadena et al. reported the use of recombinant $C B M 3 b$, originally from Paenibacillus barcinonensis endoglucanase Cel9B, to alter the cellulose fiber surface and thus improve the paper properties. ${ }^{12}$ A patented product composed of fragrance-bearing particles conjugated to CBMs was added to laundry powder, thereby reducing the amount of fragrance needed in the product. ${ }^{13}$

In recent decades, several works have reported the encapsulation of active compounds into liposomes for health and cosmetics applications. ${ }^{14-16}$ The liposomes have the capacity to entrap different kinds of molecules and can be

Received: May 10, 2019

Accepted: July 8, 2019

Published: July 8, 2019 
functionalized for a specific target. In our previous work, we explored the application of liposomes functionalized with OBP-I as nanodevices for odorant molecule retention useful for textile and cosmetic applications. ${ }^{17}$ In Nature, odorant binding proteins (OBPs) have the capacity to bind and release fragrances. ${ }^{18}$ Silva et al. explored, for the first time, the use of pig OBP-I to functionalize cotton fabrics, by electrostatic affinity, for the release of fragrances and the reduction of unpleasant odors, like cigarette smoke. ${ }^{19}$

In this work, we explored two strategies for the release of $\beta$ citronellol from cotton functionalized with CBM-based fusion proteins. In the first strategy, pig OBP-I from Sus scrofa was fused with the $\mathrm{CBM}_{\mathrm{N} 1}$ from Cellulomonas fimi (OBP::GQ $\mathrm{G}_{20}: \mathrm{CBM}$ ) and incubated with the fragrance prior to cotton functionalization. In the second strategy, the $\mathrm{CBM}_{\mathrm{N} 1}$ was fused with SP-DS3 peptide (CBM::GQ $\left.{ }_{20}:: S P-D S 3\right)$ to anchor the protein in the liposomes containing the fragrance. The CBM:: $\mathrm{GQ}_{20}:: \mathrm{SP}-\mathrm{DS} 3$-liposome complex was further applied on cotton. Both fusion proteins were designed by including a spacer $\left(\mathrm{GQ}_{20}\right)$ to confer conformational mobility to the fused partners. ${ }^{17,20,21}$ For both strategies, the release profile was evaluated by GC-MS considering the response to an external stimulus (acidic sweat solution, $\mathrm{pH}=4.3 \pm 0.2$, as indicated in AATCC method 15-2009 "Colorfastness to Perspiration"). The release of $\beta$-citronellol triggered by acidic sweat solution mimicks the conditions of perspiration relying on the dissociation of the fragrance from OBP and on the release from liposomes.

The two approaches here presented were designed to develop new cosmetotextiles for the release of fragrances. This technological solution can stimulate the textile industry in the search for new solutions creating a set of new perspirationrelated products.

\section{MATERIALS AND METHODS}

2.1. Reagents. Tris-base, imidazole, sodium phosphate, sodium chloride, cholesterol, and SPME fiber (100 $\mu$ m polydimethylsiloxane) were acquired from MerckSigma, Spain. Nickel Magnetic Beads for His Tag Protein Purification are available from Biotool, Bimake, Spain. GRS Protein Marker Blue and GRS Unstained Protein Marker were purchased from GRISP, Portugal, as well as the culture medium. 1-Aminoanthracene (96\%), $\beta$-citronellol (92\%), coumarin (99\%), vanillin (98\%), and eugenol (99\%) were acquired from TCI chemicals, Belgium. 1,2-Dioleoyl-sn-glycero-3-phosphoethanolamine (DOPE) and 1,2-distearoyl-sn-glycero-3-phosphoethanolamine- $N$ [amino(polyethylene glycol)-2000] (DSPE-PEG) were purchased from Lipoid, Canada. All other reagents were acquired from MerckSigma, Spain, and used as received. Cotton with 36 warp yarns $\times 35$ weft yarns $/ \mathrm{cm}$ and $47.3 \mathrm{~g} / \mathrm{m}^{2}$ was used. The acidic sweat solution was prepared following the AATCC Test Method 15-2009.

2.2. Design of CBM-Fusion Proteins. In this study, two fusion proteins were synthesized. The sequence of OBP-I (PDB ID 1DZK, from pig Sus scrofa) was fused with a spacer composed by 20 repetitions of glycine-glutamine residues $\left(\mathrm{GQ}_{20}\right)$ and with the $\mathrm{CBM}_{\mathrm{N} 1}$ sequence (PDB ID 1ULP, from bacteria Cellulomonas fimi). This fusion protein was designated as $\mathrm{OBP}:: \mathrm{GQ}_{20}:: \mathrm{CBM}$. In the second protein, the $\mathrm{CBM}_{\mathrm{N} 1}$ was fused with the $\mathrm{GQ}_{20}$ spacer and with the SPDS3 (DRDDQAAWFSQY) anchor peptide (CBM::GQ 20 ::SP-DS3). The gene sequences were synthesized by GenScript, USA, and cloned in pET-28a plasmid. During design, the SP-DS3 sequence was intentionally fused at the $\mathrm{C}$-terminal to maintain availability of the last five amino acids, which are involved in the anchorage to the liposomal membrane. ${ }^{22}$ As observed in our previous work, the presence of OBP in the $\mathrm{N}$-terminal helps the production of some proteins and peptides. ${ }^{17,23}$ Herein, the fusion of OBP to the CBM was performed at the $\mathrm{N}$-terminal to increase the yield of protein production.
2.3. Expression and Purification of CBM-Fusion Proteins. Both proteins were produced in Escherichia coli BL21(DE3) using Terrific Broth (TB) medium containing kanamycin. OBP:: $\mathrm{GQ}_{20}:: \mathrm{CBM}$ was expressed at $37^{\circ} \mathrm{C}, 180 \mathrm{rpm}$ during $24 \mathrm{~h}$, while CBM:: $\mathrm{GQ}_{20}:: \mathrm{SP}-\mathrm{DS} 3$ was expressed at $37{ }^{\circ} \mathrm{C}$ and $180 \mathrm{rpm}$, until the culture reached $\mathrm{OD}=0.6$, and then the temperature was decreased for $18{ }^{\circ} \mathrm{C}$ and the culture was induced for an additional 16 h. Cells were harvested by centrifugation and lysed by sonication following the procedure described by Gonçalves et al. ${ }^{17}$ Soluble and insoluble fractions were separated by centrifugation at $12,000 \times g$, for $30 \mathrm{~min}$ at $4{ }^{\circ} \mathrm{C}$. The proteins were purified from the soluble fraction using nickel magnetic beads with specificity to His-tag present in the protein's N-terminal, as described by Gonçalves et al. ${ }^{17}$ To remove salts and imidazole after purification, the samples were desalted using a Sephadex G-25 in PD-10 Desalting Column (GE Healthcare, Spain). The expression and characterization of OBP::GQ $\mathrm{GQ}_{20}: \mathrm{CBM}$ and CBM:: $\mathrm{GQ}_{20}$ ::SP-DS3 fusion proteins were performed following Gonçalves et al. ${ }^{17}$ (data not shown).

2.4. Binding Characterization of $\mathrm{OBP}:: \mathrm{GQ}_{20}:: \mathrm{CBM}$. 2.4.1. $\mathrm{Li}-$ gand-Binding Assays. The binding capacity of OBP::GQ $\mathrm{GQ}_{20}:: \mathrm{CBM}$ was determined by direct titration with 1-aminoanthracene (1-AMA, ligand model), as reported by Gonçalves et al. ${ }^{19,23}$ Briefly, increasing concentrations of 1-AMA were added to a fixed concentration of protein $(1 \mu \mathrm{M})$ and incubated at $37^{\circ} \mathrm{C}$ for $1 \mathrm{~h}$, in Tris- $\mathrm{HCl}, 50 \mathrm{mM}$, $\mathrm{pH}$ 7.5. The fluorescence of the OBP-ligand complex, after excitation at $295 \mathrm{~nm}$, was measured at $481 \mathrm{~nm}$. Measurements were recorded in triplicate, on a microplate spectrofluorometer (BioTek Synergy MX) equipped with a temperature controller. Dissociation constant $\left(K_{\mathrm{d}}\right)$ for 1-AMA was calculated from a plot of fluorescence intensity versus concentration of ligand, obtained with a standard nonlinear regression method, described in Malpeli et al. ${ }^{24}$ The association constant $\left(K_{\mathrm{a}}\right)$ was determined by $1 / K_{\mathrm{d}}\left(\mu \mathrm{M}^{-1}\right)$.

2.4.2. Competitive Binding Assays. The fluorescent competitive assays were tested using four odorant molecules: $\beta$-citronellol, coumarin, vanillin, and eugenol. Briefly, $1 \mu \mathrm{M}$ of $\mathrm{OBP}:: \mathrm{GQ}_{20}:$ :CBM in Tris- $\mathrm{HCl}, 50 \mathrm{mM}, \mathrm{pH} 7.5$, was incubated with $2 \mu \mathrm{M}$ of 1-AMA (fluorescent reporter) at $37^{\circ} \mathrm{C}$, for $1 \mathrm{~h}$. Then, $1,2,3,10,30$, and 100 $\mu \mathrm{M}$ of fragrances were added and incubated in the same conditions. The fluorescence was measured in triplicate at $481 \mathrm{~nm}$, using an excitation wavelength of $295 \mathrm{~nm}$. The dissociation constant for each fragrance was determined following the equation indicated by Gonçalves et al. ${ }^{17}$ The association constant $\left(K_{\mathrm{a}}\right)$ was determined by $1 / K_{\mathrm{d}}\left(\mu \mathrm{M}^{-1}\right)$

2.5. Preparation of $\mathrm{CBM}:: \mathrm{GQ}_{20}:: \mathrm{SP}-\mathrm{DS} 3$-Liposome/ $\boldsymbol{\beta}$-Citronellol Complex. Liposomes were prepared as described by Gonçalves et al., ${ }^{17}$ through a modified ethanol injection method. Briefly, $100 \mu \mathrm{M}$ of $\mathrm{CBM}: \mathrm{GQ}_{20}$ ::SP-DS3 protein and $1 \mathrm{mM}$ of $\beta$ citronellol, both dissolved in $50 \mathrm{mM}$ of Tris- $\mathrm{HCl} \mathrm{pH} 7.5$ (prepared in $\mathrm{upH}_{2} \mathrm{O}$ ), were added to a beaker preheated at $50{ }^{\circ} \mathrm{C}$, followed by the stepwise addition of lipids in ethanol $100 \%$. The mixture was subjected to agitation $(250 \mathrm{rpm})$ during 5-10 min to evaporate the ethanol. Afterward, the complex was hydrated in $50 \mathrm{mM}$ Tris- $\mathrm{HCl} \mathrm{pH}$ 7.5 buffer, and the agitation was maintained for $10 \mathrm{~min}$. To remove the free components (protein and fragrance) from the liposomal formulation, the samples were centrifuged across the centrifugal filter tubes with a $100 \mathrm{kDa}$ of cutoff (Vivaspin 500, GE Healthcare, Spain).

The efficiency of protein anchorage in the liposomes was assessed by SDS-PAGE and determined by the integration of the band intensities corresponding to the free and the functionalized proteins, using the ImageJ software. For that, the initial amount of protein used in this formulation $(100 \mu \mathrm{M})$, the $\mathrm{CBM}: \mathrm{GQ}_{20}$ ::SP-DS3-liposome complex and the free protein, were run in a gel. The analysis in Image allowed us to determine the functionalization efficiency by comparison with reference bands of the molecular weight marker. ${ }^{17}$

The amount of $\beta$-citronellol encapsulated into liposomes was indirectly quantified by GC-MS by the difference between the initial concentration of fragrance added to liposomes $(1000 \mu \mathrm{M})$ and the free $\beta$-citronellol (nonencapsulated) separated through a $100 \mathrm{kDa}$ cutoff membrane. 
The mean size diameter $(\mathrm{nm})$, the polydispersity index (PDI), and the surface charge $(\mathrm{mV})$ of $\mathrm{CBM}: \mathrm{GQ}_{20}:: \mathrm{SP}$-DS3-liposome/ $\beta$ citronellol complex (in buffer) were characterized by dynamic light scattering (DLS). All measurements were done in triplicate and the results described as mean \pm standard deviation.

2.6. Effect of Acidic Sweat Solution on the Properties of Carbohydrate-Binding Module (CBM)-Based Complexes. The acidic sweat solution was prepared following the AATCC method 152009 "Colorfastness to Perspiration". According to the standard procedure, the final $\mathrm{pH}$ of the acidic sweat solution should be $4.3 \pm$ 0.2 and any adjustment should be done. If this value is not achieved a new solution must be prepared.

To study the effect of acidic sweat solution on the physicochemical stability of the $\mathrm{CBM}:: \mathrm{GQ}_{20}$ ::SP-DS3-liposome/ $\beta$-citronellol complex, the size and polydispersity of the samples were assessed after incubation with an acidic sweat solution $(\mathrm{pH}=4.3 \pm 0.2)$ and with 50 $\mathrm{mM}$ Tris- $\mathrm{HCl} \mathrm{pH} 7.5$ buffer, for $1 \mathrm{~h}$ at $37^{\circ} \mathrm{C}$. The nonfunctionalized liposomes were incubated under the same conditions and used as control. Sample analysis were diluted with water 1:1000 and read in triplicate using NanoSight NS500 instrument (Salisbury, UK).

The effect of acidic sweat solution on the $\mathrm{OBP}:: \mathrm{GQ}_{20}:: \mathrm{CBM} / \beta$ citronellol complex was evaluated according to the assay described in section 2.4.2 (competitive binding assays).

2.7. Optimization of Cotton Fabrics Functionalization with OBP::GQ ${ }_{20}:: C B M$ and $C B M:: G_{20}:: S P-D S 3-L i p o s o m e$ Complex. Cotton fabrics were previously washed with a nonionic detergent, Lutensol AT25, according to ISO 105-CO3-1978 standard $\left(50{ }^{\circ} \mathrm{C}\right.$ for $60 \mathrm{~min}$ ), followed by washing with tap water and $\mathrm{dH}_{2} \mathrm{O}, 2-3$ times, under the same conditions.

Cotton fabrics $\left(3 \times 3 \mathrm{~cm}^{2}\right)$ were incubated with 5,10 , and $20 \mu \mathrm{M}$ of OBP:: $\mathrm{GQ}_{20}:: \mathrm{CBM} / \beta$-citronellol and $\mathrm{CBM}:: \mathrm{GQ}_{20}:: \mathrm{SP}-\mathrm{DS} 3$-liposome/ $\beta$-citronellol complex, at $37{ }^{\circ} \mathrm{C}$ under shaking agitation $(40$ $\mathrm{rpm}$ ) for $1 \mathrm{~h}$. Control experiments were performed by incubating the cotton only with $50 \mathrm{mM}$ Tris- $\mathrm{HCl} \mathrm{pH} \mathrm{7.5.} \mathrm{After} \mathrm{functionalization,} \mathrm{the}$ fabrics were washed $(3 \times)$ with $50 \mathrm{mM}$ Tris- $\mathrm{HCl} \mathrm{pH} 7.5$ to remove the loosely bound protein.

The amount of CBM-fused proteins adsorbed onto cotton fabrics was evaluated by (i) measurement of the absorbance at $280 \mathrm{~nm}$ $(\mathrm{A} 280 \mathrm{~nm})$ of unbound protein and by (ii) dyeing of fabrics with $1 \%$ Coomassie Brilliant Blue solution and $K / S$ evaluation (color staining levels) at maximum absorbance wavelength, measured with an Color Reflectance Spectrophotometer, (Spectraflash 600 Plus CT from Datacolor International) coupled to a computer. Calibration curves at $280 \mathrm{~nm}$ were performed using each protein as a standard.

2.7.1. Morphologic Characterization of Functionalized CottonScanning Electron Microscopy (SEM) and Energy-Dispersive X-ray Spectroscopy (EDS). The cotton fabrics functionalized with OBP::GQ $\mathrm{GQ}_{20}:: \mathrm{CBM}$ and $\mathrm{CBM}:: \mathrm{GQ}_{20}:: \mathrm{SP}-\mathrm{DS} 3$-liposome complex and the control fabrics were dried in an oven, followed by freeze-drying. Afterward, the samples were added to aluminum pin stubs with electrically conductive carbon adhesive tape (PELCO Tabs), without coating. The aluminum pin stub was then placed inside a Phenom Charge Reduction Sample Holder (CHR), and different points of the sample were analyzed for elemental composition. The cotton samples were characterized using a desktop scanning electron microscope (SEM) coupled with energy-dispersive X-ray spectroscopy (EDS) analysis (Phenom ProX with EDS detector; Phenom-World BV, Netherlands). All results were acquired using ProSuite software integrated with Phenom Element Identification software, allowing the quantification of the elements present in the samples, expressed in either weight or atomic concentration. EDS analysis was conducted at $15 \mathrm{kV}$ with an intensity map.

2.8. Evaluation of $\beta$-Citronellol Release from Functionalized Fabrics. This work proposes the development of two different approaches for fragrance release from cotton functionalized with CBM-based complexes, OBP::GQ $\mathrm{GQ}_{20}: \mathrm{CBM}$ and $\mathrm{CBM}:: \mathrm{GQ}_{20}:: \mathrm{SP}-$ DS3-liposome. The release of $\beta$-citronellol from functionalized cotton was evaluated according to the ISO 17299:2014 test standard procedure.
The calibration curves were prepared using increasing concentrations of $\beta$-citronellol $(10-100 \mu \mathrm{M}, 50 \mu \mathrm{L})$ and the SPME fiber is inserted in the middle ( $\sim 40 \mathrm{~mm}$ from top) of the GC vial $(22.5 \times$ $75.5 \mathrm{~mm}$, septa of silicone blue transparent/PTFE white, Enzymatic, Portugal) for exposure during $0.5,2,7,15$, and $23 \mathrm{~h}$. The dilutions of the fragrance were performed using $50 \mathrm{mM}$ Tris- $\mathrm{HCl} \mathrm{pH} 7.5$ prepared with $\mathrm{upH}_{2} \mathrm{O}$.

For the quantification of $\beta$-citronellol, no internal standard was added since most of the standards belong to the odorant class having the capacity to bind to the OPB pocket, ${ }^{25-28}$ thus acting as competitors of $\beta$-citronellol. Additionally, the matrix effects of cotton, acidic sweat solution, and liposomes in the GC-MS experiments were controlled using the same conditions of the samples.

The specific conditions used in each strategy are presented in more detail at sections 2.8.1 and 2.8.2.

2.8.1. Approach 1: OBP::GQ $Q_{20}:: C B M / \beta$-citronellol. OBP::GQ $\mathrm{GQ}_{20}: \mathrm{CBM}$ protein $(20 \mu \mathrm{M})$ was incubated in a flask with $\beta$-citronellol $(40 \mu \mathrm{M})$ for $1 \mathrm{~h}$, at $37^{\circ} \mathrm{C}$, to promote the binding. A $1: 2$ proportion (protein:fragrance) was based on previous competitive assays (section 2.4.2). After binding, $50 \mu \mathrm{L}$ of the OBP::GQ ${ }_{20}:: \mathrm{CBM} /$ $\beta$-citronellol complex was transferred to a new flask containing the cotton sample $\left(1.5 \times 1.5 \mathrm{~cm}^{2}\right)$, prewetted at $37{ }^{\circ} \mathrm{C}$ in $50 \mathrm{mM}$ Tris$\mathrm{HCl} \mathrm{pH} 7.5$ buffer, and incubated for $1 \mathrm{~h}$ at $37^{\circ} \mathrm{C}$. These conditions were previously optimized by our group ${ }^{19}$ and this temperature is considered optimal for CBM activity. ${ }^{29-31}$ The functionalized cotton was then transferred to a GC vial and $50 \mu \mathrm{L}$ of an acidic sweat solution ( $\mathrm{pH} 4.3 \pm 0.2)$ prepared according to AATCC Test Method 15-2009 was added to the fabric to trigger the release of $\beta$-citronellol from the OBP protein, followed by insertion of SPME fiber during $0.5,2,7,15$, and $23 \mathrm{~h}$, at $37^{\circ} \mathrm{C}$ (total time with sweat of $1.5,3,8,16$ and $24 \mathrm{~h}$ ). The amount of fragrance released was evaluated following the procedure described in section 2.8.3.

2.8.2. Approach 2: $C B M:: G Q_{20}:: S P$-DS3-liposome/ $\beta$-citronellol Complex. In a flask, $50 \mu \mathrm{L}$ of $\mathrm{CBM}_{\mathrm{A}}: \mathrm{GQ}_{20}:: \mathrm{SP}-\mathrm{DS} 3$-liposome complex, encapsulating $1 \mathrm{mM}$ of $\beta$-citronellol, was incubated with prewetted cotton in $50 \mathrm{mM}$ Tris- $\mathrm{HCl} \mathrm{pH} 7.5$ buffer $\left(1.5 \times 1.5 \mathrm{~cm}^{2}\right)$ at $37^{\circ} \mathrm{C}$ and incubated for $1 \mathrm{~h}$ at $37^{\circ} \mathrm{C}$. The functionalized cotton was transferred to a GC vial and $50 \mu \mathrm{L}$ of acidic sweat solution ( $\mathrm{pH} 4.3 \pm$ 0.2 ) prepared according to AATCC Test Method 15-2009 was added to trigger the $\beta$-citronellol release from the liposomes. This step is followed by insertion of SPME fiber in a vial tube and incubation during $0.5,2,7,15$, and $23 \mathrm{~h}$, at $37{ }^{\circ} \mathrm{C}$. The amount of fragrance released was evaluated following the procedure described in section 2.8.3.

2.8.3. Quantification of $\beta$-Citronellol Release by HeadspaceSPME/GC-MS. The release of fragrance was carried out via headspace (HS) by exposing the SPME fiber (100 $\mu$ m polydimethylsiloxane) to the vapor phase above the sample matrix, followed by gas chromatography-mass spectrometry (GC-MS) evaluation. The SPME fiber was inserted in the middle of the vial containing the sample and acidic sweat solution and exposed for several periods of time $(0.5,2,7,15$, and $23 \mathrm{~h})$ corresponding to a total time of exposure to the acidic sweat stimulus of $1.5,3,8,16$, and $24 \mathrm{~h}$, at 37 ${ }^{\circ} \mathrm{C}$. The main goal of this work is to demonstrate the functionality of textiles in the case of stress or physical exercise, where the skin temperature $\left(32-33{ }^{\circ} \mathrm{C}\right)$ can reach $36-37{ }^{\circ} \mathrm{C}$, with consequent perspiration. ${ }^{32}$ For this reason, we have chosen $37^{\circ} \mathrm{C}$ to perform the study.

The samples were quantified by GC-MS using manual injection of the SPME fiber. Gas chromatographic analyses were carried out using a Varian 4000 system with a split/splitless injector coupled to a mass spectrometer. Injections were operated at $250{ }^{\circ} \mathrm{C}$ in the split mode 1:10 using a Rxi-5Sil MS (Restek) column $(30 \mathrm{~m} \times 0.25 \mathrm{~mm}$, and $0.25 \mu \mathrm{m}$ film thickness), with a column-head pressure of $7.3 \mathrm{psi}$ using helium as carrier gas. The oven temperature started at $45^{\circ} \mathrm{C}$ and was held for $5 \mathrm{~min}$, and the temperature increased until $250{ }^{\circ} \mathrm{C}$ at a rate of $7{ }^{\circ} \mathrm{C} / \mathrm{min}$. A full scan mode $(50-750 \mathrm{~m} / z)$ was applied for the identification of the target compound. The mass spectrometer (MS) was operated in electron ionization (EI) mode at $70 \mathrm{eV}$ with total ion chromatogram (TIC) detection mode for quantitative determination 


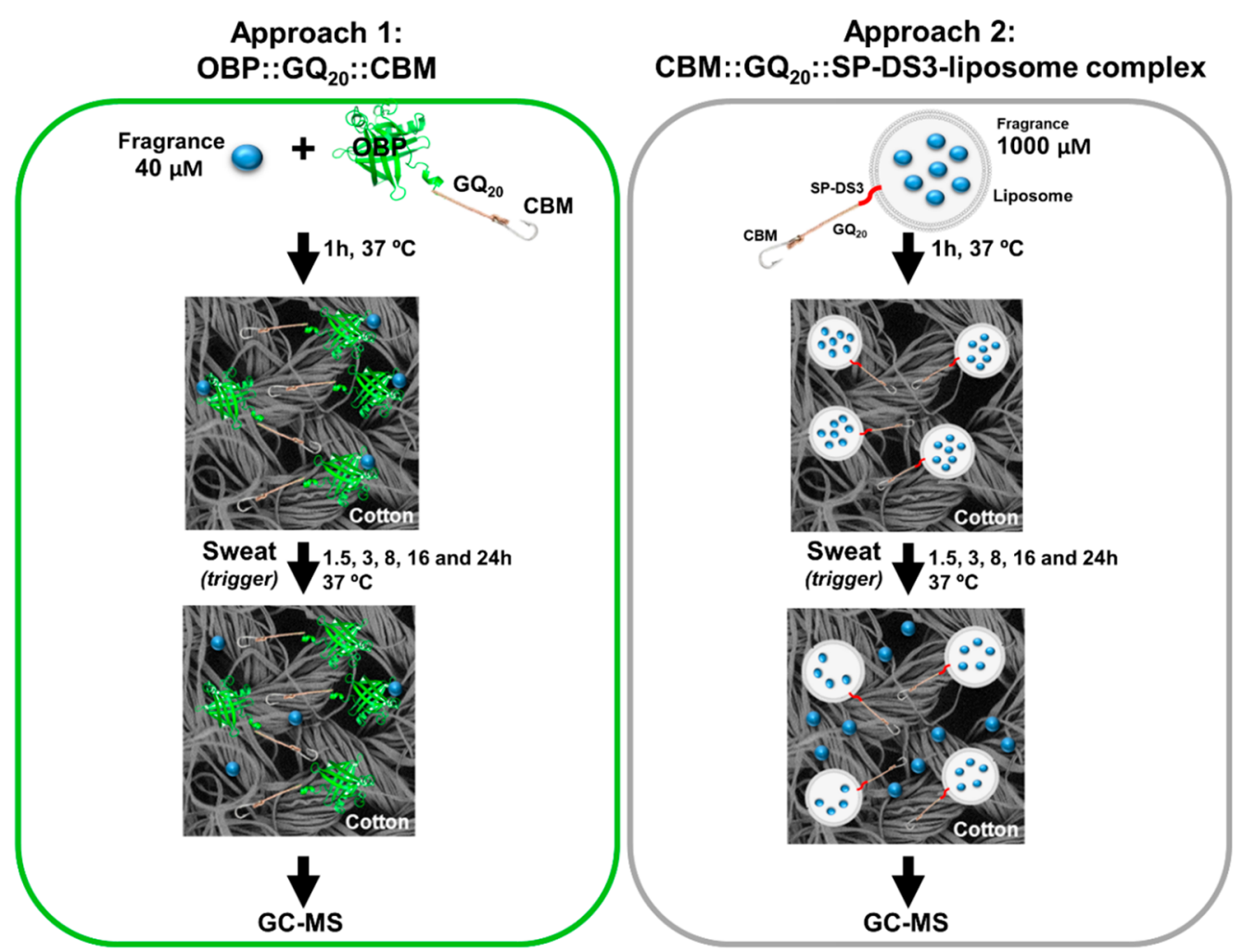

Figure 1. Schematic presentation of $\beta$-citronellol release from functionalized fabrics.

and $\mathrm{S} / \mathrm{N}$ ratio of 5 . Calibration curves of $\beta$-citronellol were determined using the same conditions of the samples (temperature and time). Each time point was evaluated separately, and all the measurements were done in duplicate. The amount of $\beta$-citronellol was determined by integration of the peaks from chromatograms and quantified against the calibration curves.

\section{RESULTS AND DISCUSSION}

3.1. Strategies for $\beta$-Citronellol Release from Functionalized Cotton Fabrics. Two strategies for $\beta$-citronellol release from cotton functionalized with CBM-based complexes, OBP::GQ $\mathrm{G}_{20}: \mathrm{CBM}$ and $\mathrm{CBM}: \mathrm{GQ}_{20}:: \mathrm{SP}-\mathrm{DS} 3$-liposome, are proposed here. In the first strategy, $\mathrm{OBP}: \mathrm{GQ}_{20}:: \mathrm{CBM}$ protein $(20 \mu \mathrm{M})$ is incubated with $40 \mu \mathrm{M} \beta$-citronellol to promote the binding of the fragrance to the protein. The OBP::GQ $\mathrm{G}_{20}: \mathrm{CBM} / \beta$-citronellol complex is then applied for cotton functionalization. The release of the fragrance from OBP is triggered by an acidic sweat solution and measured by GC-MS chromatography. In the second strategy, liposomes with $\mathrm{CBM}: \mathrm{GQ}_{20}:: \mathrm{SP}-\mathrm{DS} 3$ anchored in the membrane and encapsulating $1000 \mu \mathrm{M}$ of $\beta$-citronellol are used for cotton functionalization. As for the strategy 1 , the release of $\beta$ citronellol from liposomes is herein triggered by addition of an acidic sweat solution and evaluated by GC-MS (Figure 1).

The selection of the fragrance was made based on the binding properties of OBP. The binding affinity of OBP::GQ $\mathrm{G}_{20}: \mathrm{CBM}$ was evaluated using 1-AMA as model ligand, at $\mathrm{pH}$ 7.5. The ligand revealed a high affinity to the protein at this $\mathrm{pH}$ value $\left(K_{\mathrm{a}}=2.56 \pm 0.04 \mu \mathrm{M}\right)$ (Table 1$)$. The binding of several fragrances to the OBP was determined by competitive assays to select the molecule with the best affinity toward the protein. These studies indicate that $\beta$-citronellol is the fragrance with the highest affinity toward OBP (Table 1).
Table 1. Association Constants $\left(K_{\mathrm{a}}\right)$ of OBP::GQ $\mathrm{G}_{20}: \mathrm{CBM}$ for 1-AMA (Ligand Model) and Four Fragrances $(\beta$ Citronellol, Coumarin, Vanillin, and Eugenol) at $37^{\circ} \mathrm{C}$, at $\mathrm{pH} 7.5$ for $1 \mathrm{~h}$

\begin{tabular}{|c|c|c|c|c|}
\hline \multicolumn{5}{|c|}{ Association constants $(\mathbf{K a})\left(\boldsymbol{\mu M ^ { - 1 }}\right)$} \\
\hline 1-AMA & $\boldsymbol{\beta}$-citronellol & Coumarin & Vanillin & Eugenol \\
\hline $2.56 \pm 0.04$ & $4.17 \pm 0.05$ & $0.21 \pm 0.02$ & $0.18 \pm 0.01$ & $0.31 \pm 0.04$ \\
\hline
\end{tabular}

The amount of $\mathrm{CBM}: \mathrm{GQ}_{20}:: \mathrm{SP}-\mathrm{DS} 3$ protein anchored in the liposomal membrane was assessed by SDS-PAGE gel electrophoresis (Figure S1A). The amount of anchored protein was estimated using the ImageJ analysis, by comparison of liposomal formulation band intensity with the specific bands of the molecular weight marker, as reported in Gonçalves et al. ${ }^{17}$ The analysis inferred that about $99 \%$ of CBM::GQ ${ }_{20}:: S P-D S 3$ is anchored in the membrane of liposomes.

The nonencapsulated $\beta$-citronellol was separated from liposomes through a membrane with $100 \mathrm{kDa}$ of cutoff and quantified using GC-MS. The GC-MS spectrum for quantification of nonencapsulated $\beta$-citronellol does not present any peak related with $\beta$-citronellol (Figure S1B), demonstrating that the fragrance is associated to the complexes. Additionally, the CBM::GQ ${ }_{20}:$ :SP-DS3-liposome/ $\beta$-citronellol complex not subjected to the trigger was evaluated by GC-MS. We quantified around $50 \mu \mathrm{M}$ of $\beta$ citronellol, suggesting that some fragrance might be absorbed in the liposomal membrane.

The stability of the CBM::GQ $\mathrm{GQ}_{20}:$ SP-DS3-liposome/ $\beta$ citronellol complex and nonfunctionalized liposomes was evaluated over time in terms of size, polydispersity, and 
Table 2. CBM-Based Complex Characterization ${ }^{a}$

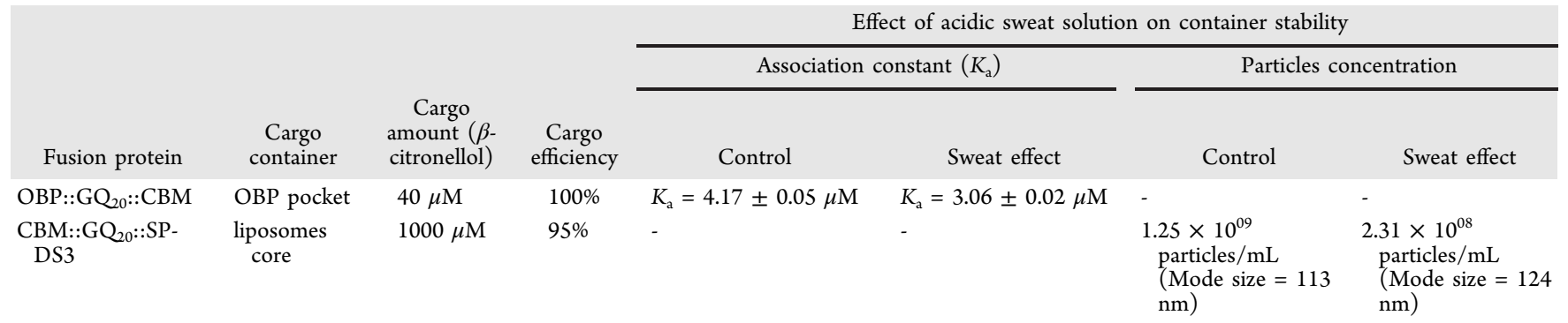

${ }^{a}$ Cargo container, cargo amount, cargo efficiency, association constant $\left(K_{\mathrm{a}}\right)$ of $\beta$-citronellol to OBP fusion-protein in buffer and acidic sweat solution, and the effect of buffer and acidic sweat solution on the stability of liposomes functionalize with CBM::GQ $20:$ SP-DS3 protein and encapsulating $\beta$-citronellol).

surface charge, by dynamic light scattering (DLS). The liposomes were shown to be stable until 24 weeks ( 6 months) of storage at $4{ }^{\circ} \mathrm{C}$. The nonfunctionalized liposomes were narrow and of small size (around of $121 \mathrm{~nm}$ ), with a monodisperse character $(\mathrm{PDI} \approx 0.158$ ) (Figure S2A), and a negative surface charge $(\sim-36 \mathrm{mv})$ (Figure $\mathrm{S} 2 \mathrm{~B})$. The CBM:: $\mathrm{GQ}_{20}:: \mathrm{SP}-\mathrm{DS} 3$-liposome/ $\beta$-citronellol complex also showed a narrow and small particle size $(\sim 145 \mathrm{~nm})$ and a negative surface charge $(\sim-31 \mathrm{mV})$ (Figure S2D), revealing however higher polydispersity (PDI $\approx 0.285$ ) (Figure $\mathrm{S} 2 \mathrm{C}$ ). The higher size and polydispersity index observed for CBM:: $\mathrm{GQ}_{20}$ ::SP-DS3-liposome/ $\beta$-citronellol complex might be associated with the presence of both encapsulated $\beta$ citronellol and anchored protein.

3.2. Effect of Acidic Sweat Solution on the Properties of Carbohydrate-Binding Module (CBM)-Based Complexes. In this work, we evaluated the properties of CBMfused proteins in the presence of an acidic sweat solution (trigger for the release of fragrances), evaluated in terms of size and polydispersity for the CBM:: $\mathrm{GQ}_{20}:: \mathrm{SP}-\mathrm{DS} 3$-liposome $/ \beta$ citronellol complex and in terms of binding affinity for the OBP:: $\mathrm{GQ}_{20}:: \mathrm{CBM} / \beta$-citronellol complex. The effect of acidic sweat solution on the physicochemical properties of the functionalized liposomes containing $\beta$-citronellol, such as the average diameter and the particle concentration, was evaluated using the Nanosight particle analyzer. As in nonfunctionalized liposomes, the addition of acidic sweat solution led to an increase of functionalized liposome size and to a reduction of the particle concentration (Figure S3A-C). In the presence of acidic sweat solution, the affinity of $\beta$-citronellol to OBP decreased, as highlighted by a decrease of the association constant $\left(K_{\mathrm{a}}=3.06 \pm 0.02 \mu \mathrm{M}\right.$, Table 2$)$. These results might indicate that acidic sweat solution is a good trigger for the release of $\beta$-citronellol from both approaches since it disturbs the physicochemical properties of the liposomes and affects the binding affinity properties of OBP, ensuring a controlled release without compromising the integrity of the systems (Table 2).

3.3. Functionalization of Cotton Fabrics with OBP::GQ $\mathbf{G}_{20}:: \mathrm{CBM} / \boldsymbol{\beta}$-Citronellol and $\mathrm{CBM}:: \mathrm{GQ}_{20}:: \mathrm{SP}-\mathrm{DS} 3-$ Liposome/ $\beta$-Citronellol Complex. 3.3.1. Efficiency of Cotton Functionalization. The amount of CBM-based complexes containing $\beta$-citronellol at the surface of cotton fabrics was evaluated by dyeing the fabrics with a Coomassie blue solution (1\%). The degree of fabric functionalization is directly related with the color intensity measured in terms of $K / S$ (Figure 2). The highest level of functionalization was observed when using $20 \mu \mathrm{M}$ of proteins. The amount of CBM-

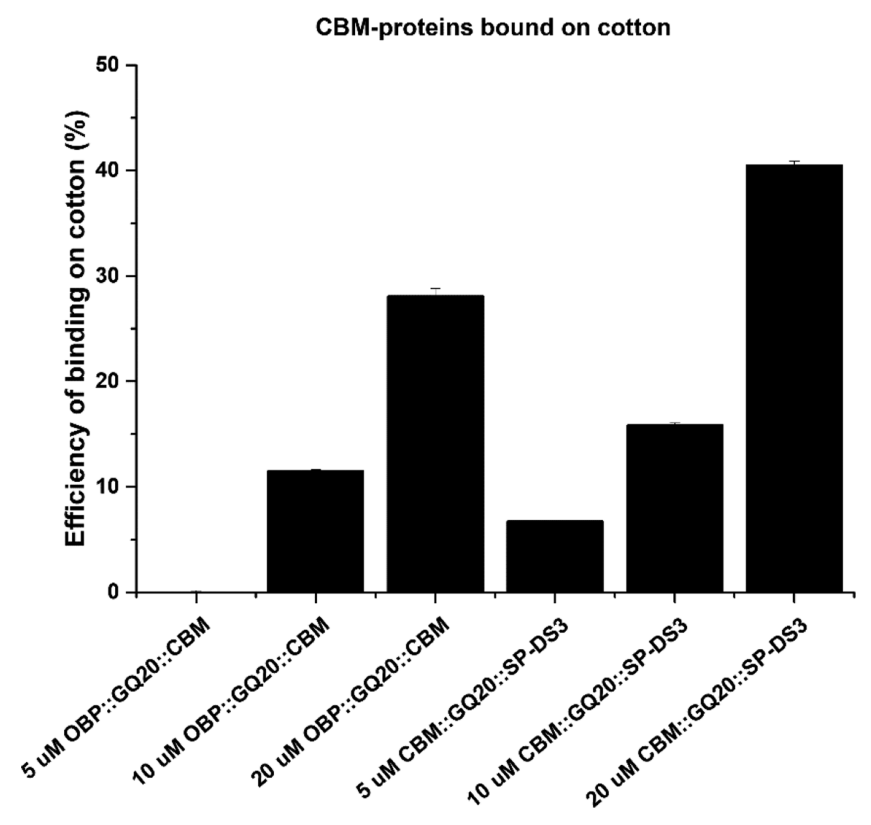

Figure 2. Amount of OBP:: $\mathrm{GQ}_{20}:: \mathrm{CBM} / \beta$-citronellol and CBM:: $\mathrm{GQ}_{20}:$ :SP-DS3-liposome/ $\beta$-citronellol complex functionalized on cotton (\%) determined by $K / S$ evaluation; the values were obtained by subtracting the $K / S$ value of buffer to the $K / S$ value of each protein concentration.

based complexes at the cotton surface, when using $20 \mu \mathrm{M}$, was determined by quantification of the unbound protein at 280 $\mathrm{nm}$ and by $K / S$ evaluation (color staining levels) at the maximum absorbance wavelength (at $610 \mathrm{~nm}$ ). The absorbance data at $280 \mathrm{~nm}$ revealed a coating efficiency of $10.4 \pm 0.1 \%$ and $12.9 \pm 2.5 \%$, for OBP::GQ ${ }_{20}:: \mathrm{CBM} / \beta$ citronellol and the CBM::GQ $\mathrm{GQ}_{20}: \mathrm{SP}-\mathrm{DS} 3$-liposome $/ \beta$-citronellol complex, respectively. The $K / S$ analysis directly correlates the color intensity of the cotton samples with the amount of protein at the surface after functionalization. The highest levels of functionalization obtained with $20 \mu \mathrm{M}$ of protein were 28.1 $\pm 0.7 \%$ and $40.5 \pm 0.4 \%$ for OBP::GQ $\mathrm{GQ}_{20}: \mathrm{CBM} / \beta$-citronellol and the CBM::GQ $20:$ SP-DS3-liposome/ $\beta$-citronellol complex, respectively (Figure 2 ).

3.3.2. Morphologic Characterization of Functionalized Fabrics-SEM and EDS. The functionalization efficiency by OBP::GQ $\mathrm{GQ}_{20}: \mathrm{CBM}$ and by the CBM::GQ $\mathrm{GQ}_{20}: \mathrm{SP}-\mathrm{DS} 3$-liposome complex was evaluated by SEM. The micrographs obtained for the CBM:: $\mathrm{GQ}_{20}:: S P-D S 3-l i p o s o m e$ complex show the presence of macroscopic particles attached to the fabrics' surface (Figure S4B), while the samples coated with 

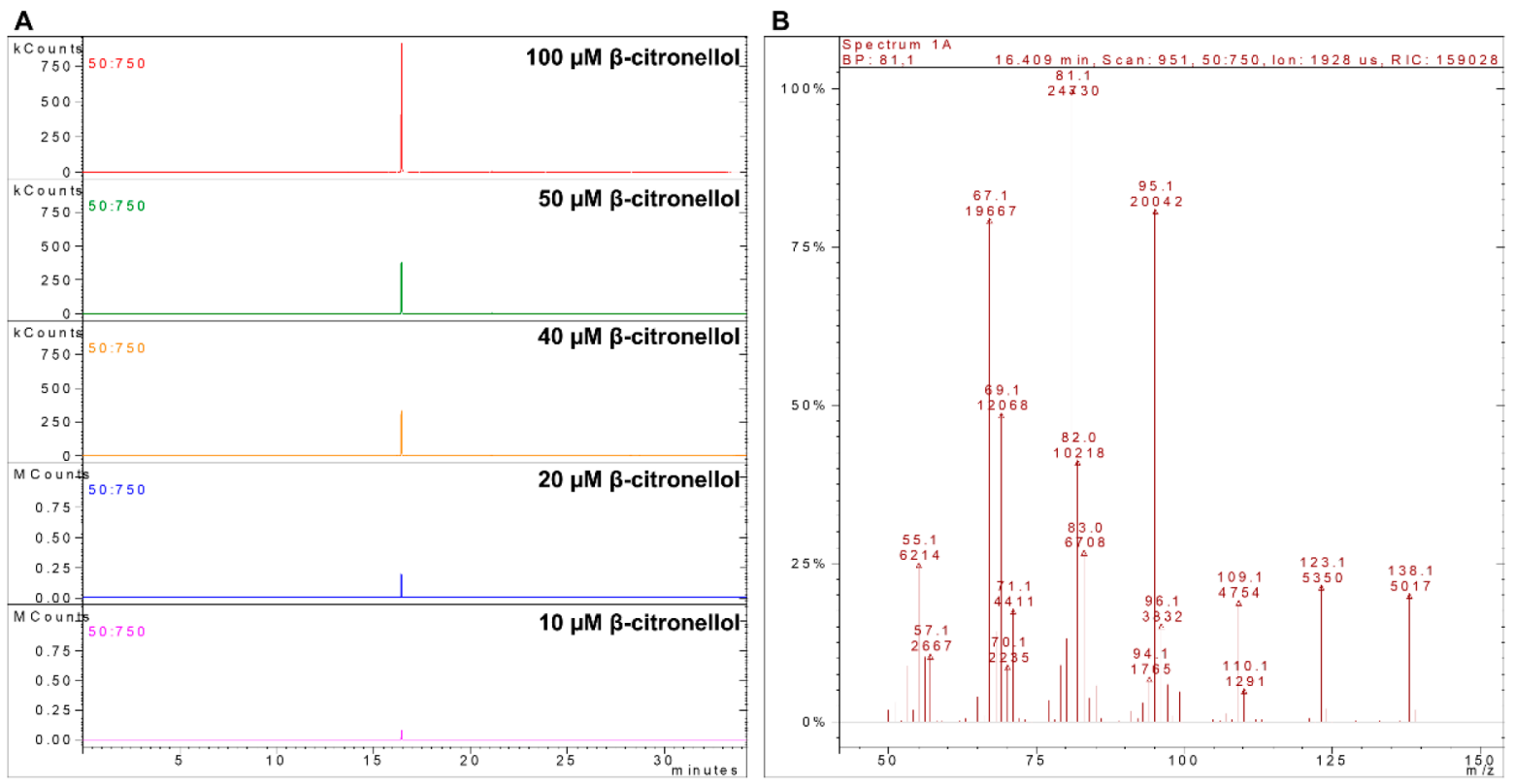

Figure 3. $\beta$-Citronellol chromatograms $(\mathrm{RT}=16.4 \mathrm{~min})$ of increasing concentrations of fragrance $(\mathrm{A})$ and mass spectra of $\beta$-citronellol $(\mathrm{B})$, observed by headspace-SPME/GC-MS.

$\mathrm{OBP}:: \mathrm{GQ}_{20}: \mathrm{CBM}$ reveal a more smooth and clean surface (Figure S4A). The quantification of the elements present in the samples was performed by energy-dispersive X-ray spectroscopy (EDS) analysis and expressed in either weight or atomic concentration (Figure S4D). The results show the presence of nitrogen $(\mathrm{N})$ on cotton coated with both OBP::GQ $\mathrm{GQ}_{20}: \mathrm{CBM}$ and CBM::GQ $\mathrm{GQ}_{20}:: \mathrm{SP}-\mathrm{DS} 3$-liposome complexes. The presence of liposomes on the cotton surface was confirmed by the presence of nitrogen as well as by the identification and quantification of phosphor $(\mathrm{P})$, even in a low amount, related to the phospholipid part of the CBM:: $\mathrm{GQ}_{20}$ ::SP-DS3-liposome complex (Figure S4D).

3.3.3. Quantification of Fragrance Release by HeadspaceSPME/GC-MS Trigger by Acidic Sweat Solution. For the design of the release systems, the implicit evaporation of the fragrance and the trigger mechanisms were considered. ${ }^{4}$ The aim of this work is the development of an efficient system for fragrance release from cotton. The experiments were performed at $37{ }^{\circ} \mathrm{C}$ to simulate the temperature increase of the skin after an external stimulus of stress or physical exercise, and an acidic sweat solution was applied to simulate the perspiration serving as a trigger for fragrance release (Figure $1)$. The calibration curves were prepared using increasing concentrations of $\beta$-citronellol at the same conditions as the samples (Figure S5). From the GC data, a unique peak was obtained (Figure 3A) corresponding to a mass spectra characteristic of $\beta$-citronellol with retention time of $16.4 \mathrm{~min}$ (Figure 3B). The chromatograms of cotton and nonfunctionalized liposomes did not reveal any peak, while the acidic sweat solution presented some peaks but with retention times different from those of $\beta$-citronellol (Figure S6). This indicates that no matrix effects arose from acidic sweat solution samples after the addition of liposomes with fragrance, therefore validating the GC-MS (SPME-HS-GC-MS) experiments.

The GC-MS results obtained for the CBM-based complex, OBP:: $\mathrm{GQ}_{20}:: \mathrm{CBM} / \beta$-citronellol, reveal that the addition of acidic sweat solution to the functionalized cotton resulted in a burst release after $1.5 \mathrm{~h}$ of exposure $(\sim 11.3 \mu \mathrm{M}, 28.3 \%)$. After this period of time, no significant release was observed at least until $24 \mathrm{~h}$ of exposure (10.3 $\mu \mathrm{M}, 25.9 \%$ ) (Figure 4). After $1.5 \mathrm{~h}$

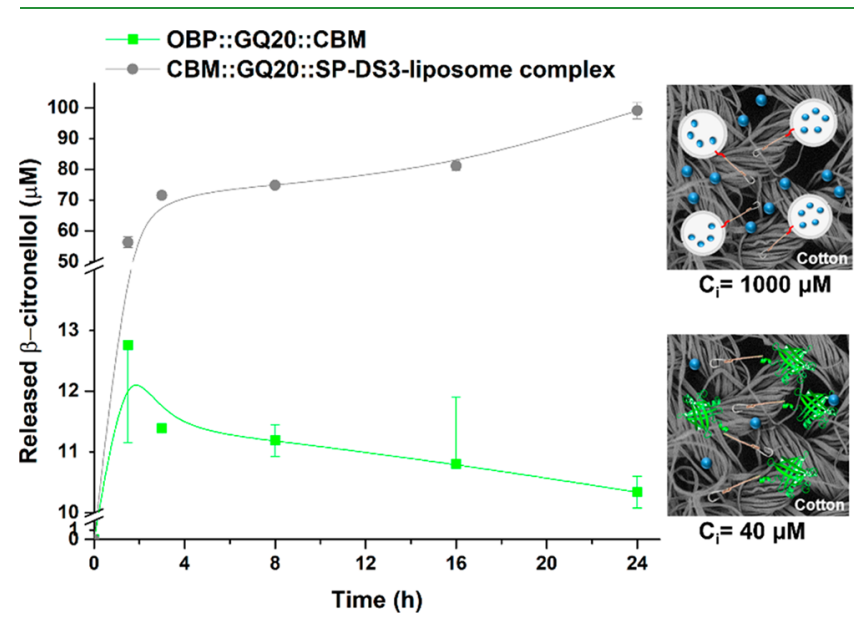

Figure 4. $\beta$-Citronellol release from cotton functionalized with $\mathrm{OBP}:: \mathrm{GQ}_{20}:: \mathrm{CBM} / \beta$-citronellol (green line) and with CBM:: $\mathrm{GQ}_{20}$ ::SP-DS3-liposome/ $\beta$-citronellol (gray line), after 1.5, 3, 8,16 , and $24 \mathrm{~h}$ of acidic sweat solution $(\mathrm{pH} 4.3 \pm 0.2)$ exposure at 37 ${ }^{\circ} \mathrm{C}$. The initial amount of $\beta$-citronellol added was $40 \mu \mathrm{M}$ when using the OBP::GQ $\mathrm{GQ}_{20}: \mathrm{CBM}$, and $1000 \mu \mathrm{M}$ when using the CBM::GQ ${ }_{20}:: S P-D S 3-$ liposome/ $\beta$-citronellol.

of exposure, the effect of acidic sweat solution as a release stimulus seems to be minimal compared to the binding ability of OBP. The release behavior of the system was governed by the acidic sweat solution stimulus for the initial $1.5 \mathrm{~h}$ reaching a plateau after this period of time (Figure 4, green line).

In the second strategy using the CBM::GQ ${ }_{20}:$ SP-DS3liposome $/ \beta$-citronellol complex, the experiments began to consider an encapsulation of around $950 \mu \mathrm{M}$ of $\beta$-citronellol (24-fold higher than used on the previous strategy). The liposomes allow the encapsulation of higher amounts of fragrance and protection against deterioration of unstable chemical groups. ${ }^{4,33}$ The data obtained reveal a burst release of 
$\beta$-citronellol after $1.5 \mathrm{~h}(\sim 56.3 \mu \mathrm{M}, 5.9 \%)$ similarly to the previous approach. However, for this strategy the fragrance release is time-dependent, increasing continuously over time, at least until the last time period evaluated $(99.1 \mu \mathrm{M}, 10.4 \%)$ (Figure 4, gray line).

The OBP:: $\mathrm{GQ}_{20}:: \mathrm{CBM}$ and the $\mathrm{CBM}:: \mathrm{GQ}_{20}:: \mathrm{SP}-\mathrm{DS} 3-$ liposome complexes are stable at $\mathrm{pH} 7.5$ (Table 1 and Figure S2); thus, this $\mathrm{pH}$ was selected to conduct the experiments. The release of $\beta$-citronellol was triggered by exposing the fabrics functionalized with the complexes to an acidic sweat solution $(\mathrm{pH} 4.3 \pm 0.2)$ which decreased the affinity of $\beta$-citronellol to OBP $\left(K_{\mathrm{a}}=3.06 \pm 0.02 \mu \mathrm{M}\right)$ when compared with its affinity at $\mathrm{pH} 7.5\left(K_{\mathrm{a}}=4.17 \pm 0.05\right)$. Moreover, the liposomes are $\mathrm{pH}$ sensitive due to the presence of DOPE in their composition. At $\mathrm{pH} 7.5$, the liposomes are stable, while at acidic $\mathrm{pH}$, there is a membrane destabilization leading to the release of the encapsulated content. ${ }^{34,35}$

Both carbohydrate-binding module (CBM)-based complexes demonstrate the potential to functionalize fabrics while carrying and releasing fragrances, namely, $\beta$-citronellol. The choice of the most prone system will depend on the final application, particularly considering the time and concentration requirements. The OBP:: $\mathrm{GQ}_{20}: \mathrm{CBM}$ complex can be used when a fast release is required $(28.3 \%$ of the initial amount, after $1.5 \mathrm{~h}$ of exposure with acidic sweat solution) while the CBM:: $\mathrm{GQ}_{20}:: S P-D S 3-$ liposome complex is indicated more when a slower and controlled release is envisaged (5.9\% of the initial amount, after $1.5 \mathrm{~h}$ of exposure with acidic sweat solution). After this time-point, the release of $\beta$-citronellol from the OBP::GQ $\mathrm{GQ}_{20}: \mathrm{CBM}$ complex seems to reach an equilibrium due to a competition between affinity and release, while a continuous release is observed when using the CBM:: $\mathrm{GQ}_{20}$ ::SP-DS3-liposome complex. Ideally, the OBP:: $\mathrm{GQ}_{20}:: \mathrm{CBM}$ could be used for the initial release a higher amount of $\beta$-citronellol and the CBM::GQ ${ }_{20}:: S P-D S 3-$ liposome for low amounts of fragrances. However, the cargo of liposomes is higher than the OBP as shown in Figure 4.

\section{CONCLUSIONS}

In light of recent developments in the textile industry, we designed two strategies based on the CBM-module, OBP::GQ ${ }_{20}:: C B M$ complex and CBM::GQ ${ }_{20}:: S P-D S 3-l i p-$ osome complex, for the functionalization of fabrics and controlled release of $\beta$-citronellol. Due to its ability to adsorb on cellulose, CBM was used to fix the proteins onto the fabrics' surface, prolonging the contact of OBP (in OBP:: $\mathrm{GQ}_{20}: \mathrm{CBM}$ complex) and of liposomes (in CBM:: $\mathrm{GQ}_{20}$ ::SP-DS3-liposome complex).

The two strategies demonstrate the potential for release of $\beta$-citronellol, however, with differentiated release profiles. The OBP:: $\mathrm{GQ}_{20}:: \mathrm{CBM} / \beta$-citronellol complex revealed the potential for applications which require a fast release of high percentages of fragrance, whereas the $C B M:: G_{20}:: S P-D S 3-$ liposome $/ \beta$-citronellol complex is more suitable for prolonged and controlled release of lower amounts of $\beta$-citronellol.

\section{ASSOCIATED CONTENT}

\section{S Supporting Information}

The Supporting Information is available free of charge on the ACS Publications website at DOI: 10.1021/acsami.9b08191.

Protein loss evaluation, nanosight particle analyzer, physicochemical characterization of liposomes, SEM and EDS analysis, and $\beta$-citronellol chromatogram validation $(\mathrm{PDF})$

\section{AUTHOR INFORMATION}

\section{Corresponding Authors}

*E-mail: carla.silva@ceb.uminho.pt.

*E-mail: artur@deb.uminho.pt.

ORCID 1

Artur Cavaco-Paulo: 0000-0001-7204-2064

\section{Author Contributions}

The manuscript was written through contributions of all authors. All authors have given approval to the final version of the manuscript.

Notes

The authors declare no competing financial interest.

\section{ACKNOWLEDGMENTS}

This study was supported by the Portuguese Foundation for Science and Technology (FCT) under the scope of the strategic funding of UID/BIO/04469/2019 unit and BioTecNorte operation (NORTE-01-0145-FEDER-000004) funded by European Regional Development Fund under the scope of Norte2020 - Programa Operacional Regional do Norte. F.G. and C.S. thanks FCT for their funding (SFRH/ BD/114684/2016; SFRH/IF/00186/2015).

\section{ABBREVIATIONS}

1-AMA, 1-aminoanthracene; DOPE, 1,2-Dioleoyl-sn-glycero-3phosphoethanolamine; DSPE-PEG, 1,2-distearoyl-sn-glycero3-phosphoethanolamine-N-[amino(polyethylene glycol)-2000; CBM, carbohydrate-binding module; CHR, Charge Reduction Sample Holder; DLS, dynamic light scattering; EDS, energydispersive X-ray spectroscopy; GC-MS, gas chromatographymass spectrometry; HS, headspace; HS-SPME, solid phase microextraction in headspace; $K_{\mathrm{a}}$, association constant; $K_{\mathrm{d}}$, dissociation constant; OBP, odorant binding protein; PDI, polydispersity index; SEM, scanning electron microscope; TIC, total ion chromatogram detection mode

\section{REFERENCES}

(1) Cherenack, K.; van Pieterson, L. Smart textiles: Challenges and Opportunities. J. Appl. Phys. 2012, 112 (9), No. 091301.

(2) Mečnika, V.; Hoerr, M.; Krievinšs, I.; Schwarz, A. Smart Textiles for Healthcare: Applications and Technologies. Rural Environment. Education. Personality 2014, 7, 150-161.

(3) Decaens, J.; Vermeersch, O. Specific Testing for Smart Textiles. Advanced Characterization and Testing of Textiles 2018, 351-374.

(4) Kaur, R.; Kukkar, D.; Bhardwaj, S. K.; Kim, K. H.; Deep, A. Potential use of Polymers and their Complexes as Media for Storage and Delivery of Fragrances. J. Controlled Release 2018, 285, 81-95.

(5) Ben Abdelkader, M.; Azizi, N.; Baffoun, A.; Chevalier, Y.; Majdoub, M. New Microcapsules based on Isosorbide for Cosmetotextile: Preparation and Characterization. Ind. Crops Prod. 2018, 123, 591-599.

(6) Hu, J.; Xiao, Z.; Zhou, R.; Li, Z.; Wang, M.; Ma, S. Synthesis and Characterization of Polybutylcyanoacrylate-encapsulated Rose Fragrance Nanocapsule. Flavour Fragrance J. 2011, 26 (3), 162-173.

(7) Martel, B.; Weltrowski, M.; Ruffin, D.; Morcellet, M. Polycarboxylic acids as crosslinking Agents for Grafting Cyclodextrins onto Cotton and Wool Fabrics: Study of the Process Parameters. J. Appl. Polym. Sci. 2002, 83 (7), 1449-1456.

(8) Oliveira, C.; Carvalho, V.; Domingues, L.; Gama, F. M. Recombinant CBM-fusion Technology - Applications Overview. Biotechnol. Adv. 2015, 33 (3-4), 358-69. 
(9) Shoseyov, O.; Shani, Z.; Levy, I. Carbohydrate Binding Modules: Biochemical Properties and Novel Applications. Microbiology and Molecular Biology Reviews: MMBR 2006, 70 (2), 283-95.

(10) Guerreiro, C. I.; Fontes, C. M.; Gama, M.; Domingues, L. Escherichia coli Expression and Purification of four Antimicrobial Peptides fused to a Family 3 Carbohydrate-binding module (CBM) from Clostridium thermocellum. Protein Expression Purif. 2008, 59 (1), $161-8$.

(11) Cavaco-Paulo, A.; Morgado, J.; Andreaus, J.; Kilburn, D. Interactions of Cotton with CBD Peptides. Enzyme Microb. Technol. 1999, 25, 639-643.

(12) Cadena, E. M.; Chriac, A. I.; Pastor, F. I.; Diaz, P.; Vidal, T.; Torres, A. L. Use of Cellulases and Recombinant Cellulose Binding Domains for refining TCF Kraft Pulp. Biotechnol. Prog. 2010, 26 (4), 960-7.

(13) Berry, M. J.; Davis, P. J.; Gidley, M. J. Conjugated Polysaccharide Fabric Detergent and Conditioning Products; U.S. Patent 6,225,462, 2001.

(14) Singh, T. G.; Sharma, N. Nanobiomaterials in Cosmetics: Current Status and Future Prospects. Nanobiomaterials in Galenic Formulations and Cosmetics 2016, 149-174.

(15) Dreher, J.; Ettl, R.; Kutschera, M. In-situ sol-gel Encapsulation of Fragrances, Perfumes or Flavours; International Patent WO2011124706A1; 2011.

(16) Teixeira, C. S. N. R. Microencapsulation of Perfumes for Application in Textile Industry; Degree of Doctor Thesis; University of Porto, 2010.

(17) Gonçalves, F.; Silva, C.; Ribeiro, A.; Cavaco-Paulo, A. 1Aminoanthracene Transduction into Liposomes Driven by OdorantBinding Protein Proximity. ACS Appl. Mater. Interfaces 2018, 10, 27531.

(18) Pelosi, P.; Mastrogiacomo, R.; Iovinella, I.; Tuccori, E.; Persaud, K. C. Structure and Biotechnological Applications of Odorant-binding Proteins. Appl. Microbiol. Biotechnol. 2014, 98 (1), 61-70.

(19) Silva, C.; Matama, T.; Azoia, N. G.; Mansilha, C.; Casal, M.; Cavaco-Paulo, A. Odorant Binding Proteins: a Biotechnological Tool for Odour Control. Appl. Microbiol. Biotechnol. 2014, 98 (8), 362938.

(20) Chen, X.; Zaro, J. L.; Shen, W. C. Fusion Protein Linkers: Property, Design and Functionality. Adv. Drug Delivery Rev. 2013, 65 (10), 1357-69.

(21) Guo, H.; Yang, Y.; Xue, F.; Zhang, H.; Huang, T.; Liu, W.; Liu, H.; Zhang, F.; Yang, M.; Liu, C.; Lu, H.; Zhang, Y.; Ma, L. Effect of Flexible Linker Length on the Activity of Fusion Protein 4-coumaroylCoA ligase::stilbene Synthase. Mol. BioSyst. 2017, 13 (3), 598-606.

(22) Nogueira, E.; Mangialavori, I. C.; Loureiro, A.; Azoia, N. G.; Sárria, M. P.; Nogueira, P.; Freitas, J.; Harmark, J.; Shimanovich, U.; Rollet, A.; Lacroix, G.; Bernardes, G. J. L.; Guebitz, G.; Hebert, H.; Moreira, A.; Carmo, A. M.; Rossi, J. P. F. C.; Gomes, A. C.; Preto, A.; Cavaco-Paulo, A. Peptide Anchor for Folate-targeted Liposomal Delivery. Biomacromolecules 2015, 16 (9), 2904-2910.

(23) Goncalves, F.; Castro, T. G.; Nogueira, E.; Pires, R.; Silva, C.; Ribeiro, A.; Cavaco-Paulo, A. OBP fused with Cell-penetrating Peptides Promotes Liposomal Transduction. Colloids Surf., B 2018, $161,645-653$.

(24) Malpeli, G.; Folli, C.; Cavazzini, D.; Sartori, G.; Berti, R. Purification and Fluorescent Titration of Cellular Retinol-Binding Protein. In Methods Mol. Biol., Redfern, C. P. F., Ed.; 1998; pp 111122.

(25) Gherghel, S.; Morgan, R. M.; Arrebola-Liébanas, J.; RomeroGonzález, R.; Blackman, C. S.; Garrido-Frenich, A.; Parkin, I. P. Development of a HS-SPME/GC-MS method for the Analysis of Volatile Organic Compounds from Fabrics for Forensic Reconstruction Applications. Forensic Sci. Int. 2018, 290, 207-218.

(26) Moreira, N.; Araújo, A. M.; Rogerson, F.; Vasconcelos, I.; de Freitas, V.; de Pinho, P. G. Development and Optimization of a HSSPME-GC-MS Methodology to Quantify Volatile Carbonyl Compounds in Port wines. Food Chem. 2019, 270, 518-526.
(27) Barbosa, A. J. M.; Oliveira, A. R.; Roque, A. C. A. Protein- and Peptide-Based Biosensors in Artificial Olfaction. Trends Biotechnol. 2018, 36 (12), 1244-1258.

(28) Vincent, F.; Ramoni, R.; Spinelli, S.; Grolli, S.; Tegoni, M.; Cambillau, C. Crystal Structures of Bovine Odorant-binding Protein in Complex with Odorant Molecules. Eur. J. Biochem. 2004, 271 (19), 3832-42.

(29) Gilkes, N. R.; Warren, A. J.; Miller, R. C.; Kilburn, D. G. Precise Excision of the Cellulose Binding Domains from Two Cellulomonas fimi Cellulases by a Homologous Protease and the Effect on Catalysis. J. Biol. Chem. 1988, 263 (21), 10401-10407.

(30) Shen, H.; Schmuck, M.; Pilz, I.; Gilkes, N. R.; Kilburn, D. G.; Miller, R. C.; Warren, A. J. Deletion of the Linker Connecting the Catalytic and Cellulose-binding Domains of Endoglucanase A (CenA) of Cellulomonas fimi Alters Its Conformation and Catalytic Activity. J. Biol. Chem. 1991, 266 (17), 11335-11340.

(31) Caspi, J.; Barak, Y.; Haimovitz, R.; Irwin, D.; Lamed, R.; Wilson, D. B.; Bayer, E. A. Effect of Linker Length and Dockerin Position on Conversion of a Thermobifida fusca Endoglucanase to the Cellulosomal mode. Applied and environmental microbiology 2009, 75 (23), 7335-42.

(32) Gisolfi, C.; Wenger, C. B. Temperature Regulation During Exercise: Old Concepts, New Ideas. Exercise Sport Sci. Rev. 1984, 12, 339-372.

(33) Liu, Y.; Liu, K.; Li, X.; Xiao, S.; Zheng, D.; Zhu, P.; Li, C.; Liu, J.; He, J.; Lei, J.; Wang, L. A novel Self-assembled Nanoparticle Platform based on Pectin-eight-arm Polyethylene Glycol-Drug Conjugates for co-delivery of Anticancer Drugs. Mater. Sci. Eng., C 2018, 86, 28-41.

(34) Nogueira, E.; Gomes, A. C.; Preto, A.; Cavaco-Paulo, A. Design of Liposomal Formulations for Cell Targeting. Colloids Surf., B 2015, $136,514-526$.

(35) Nogueira, E.; Cruz, C. F.; Loureiro, A.; Nogueira, P.; Freitas, J.; Moreira, A.; Carmo, A. M.; Gomes, A. C.; Preto, A.; Cavaco-Paulo, A. Assessment of Liposome Disruption to Quantify Drug Delivery in vitro. Biochim. Biophys. Acta, Biomembr. 2016, 1858 (2), 163-167. 